\title{
ANALISIS MATERI POKOK BAHASA INDONESIA PADA BUKU TEMATIK KELAS III MI/SD REVISI 2018
}

\author{
Umi Salma Fauziyah ${ }^{1}$ \\ ${ }^{1}$ Universitas Islam Negeri Sunan Kalijaga
}

\begin{abstract}
This study aims to determine the relevance of Indonesian language material in class 3 thematic books revised 2018 with several aspects, namely the scope of the material based on Permendikbud No. 21 2016; HOTS (Higher Order Thinking Skills); $4 C s$ (creative thinking, critical thinking, communication, \& collaboration); literacy reading; writing; digital literacy. The research method used is qualitative with the type of discourse analysis on Indonesian language material in class 3 thematic books revised 2018. The results of the study indicate the relevance of Indonesian language material in class 3 thematic books revised 2018 with aspects already mentioned with the results $46 \%$ of the material has been presented, HOTS skills are not balanced because the majority of critical thinking is $66.7 \%$ and decision making is absent, $4 C s$ skills are evenly distributed even though more critical thinking is $40.5 \%$, reading literacy is $78.9 \%$ and writing literacy is $21.1 \%$, digital literacy is discussed in a separate section which is on theme 7 subtheme 3 although the material is still an introduction stage. Overall, the Indonesian language material in Class 3 thematic books is already quite relevant to related aspects, although some are still uneven in some aspects
\end{abstract}

Keyword: Indonesian Materials, Class 3 Thematic Book

\begin{abstract}
Abstrak: Penelitian ini bertujuan untuk mengetahui relevansi dari materi bahasa Indonesia pada buku tematik kelas 3 revisi 2018 dengan beberapa aspek yaitu ruang lingkup materi berdasarkan Permendikbud No 21 tahun 2016; HOTS (Higher Order Thinking Skills); 4Cs (creative thinking, critical thinking, communication, \& collaboration); literasi membaca-menulis; literasi digital. Metode penelitian yang digunakan adalah kualitatif dengan jenis analisis wacana pada materi bahasa Indonesia di buku tematik kelas 3 revisi 2018. Hasil penelitian menunjukkan adanya relevansi antara materi bahasa Indonesia pada buku tematik kelas 3 revisi 2018 dengan aspek yang sudah disebutkan dengan hasil $46 \%$ materi sudah disajikan, keterampilan HOTS tidak imbang karena mayoritas critical thinking yaitu $66,7 \%$ dan decision making tidak ada, keterampilan 4Cs sudah merata meski critical thinking lebih banyak yaitu 40,5\%, literasi membaca persentasenya $78,9 \%$ dan literasi menulis $21,1 \%$, literasi digital dibahas pada satu bagian tersendiri yaitu pada tema 7 subtema 3 meskipun materinya masih tahap pengenalan. Secara keseluruhan materi bahasa Indonesia pada buku tematik kelas 3 sudah cukup relevan dengan aspek-aspek yang berkaitan meski ada yang masih kurang merata pada beberapa aspek.
\end{abstract}

Kata Kunci: Materi Bahasa Indonesia, Buku Tematik Kelas 3

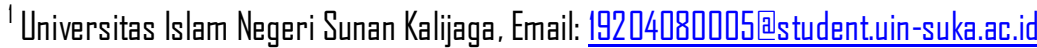




\section{PENDAHULUAN}

Era revolusi Industri saat ini semakin sering diperbincangkan di banyak tempat, karena peran teknologi-teknologi canggih pada era ini seperti menjadi kebutuhan banyak manusia, salah satu dampak berkembangnya era revolusi industri 4.0 yaitu menjadikan banyak hal semakin mudah, pada era ini juga banyak hal dapat dilakukan dengan lebih fleksibel dan cepat.

Akan tetapi di sisi lain era revolusi industri 4.0 ini juga memberikan dampak signifikan bagi banyak aspek termasuk aspek pendidikan. Pendidikan sebagaimana yang kita tahu menjadi salah satu tempat untuk mempersiapkan generasi selanjutnya dalam menghadapi tantangan masa depan. Jika pendidikan yang sekarang ada tidak mampu menjawab tantangan era revolusi industri 4.0 maka akan tertinggal dalam banyak aspek nantinya. Hal ini kemudian menjadi alasan bagi kita semua untuk segera menyesuaikan diri dengan perkembangan yang ada jika tidak ingin tertinggal.

\begin{tabular}{lllr}
\multicolumn{3}{c}{ Penyesuaian } & dalam bidang \\
pendidikan yang & bisa dilakukan \\
diantaranya & adalah & mengembangkan
\end{tabular} konten yang diterapkan pada kegiatan pembelajaran. Konten pembelajaran di masa sekarang ini sepertinya perlu mengacu pada pengembangan SDM unggul yang dapat menjawab setiap tantangan di masa depan. Kemampuan untuk menghadapi dan menjawab tantangan ini penting bagi manusia karena dengannya manusia-manusia ini mampu bertahan dan dapat berusaha berkembang. Berkaitan dengan ini maka perlu adanya evaluasi konten yang diterapkan pada sistem pendidikan sekarang.

Hasil survey PISA (The Programme for International Student Assesment) pada tahun 2018 menunjukkan bahwa Indonesia berada pada periingkat 71 dari 78 negara dalam bidang pendidikan. Dengan skor dibawah rata-rata yaitu 371 untuk membaca, 379 untuk matematika, dan 396 untuk sains. Ternyata hal ini terus berulang dari tahun ke tahun bahkan semakin menurun sejak keikutsertaan Indonesia pada tahun 2000. Ini membuat kita perlu melakukan melihat lebih dalam mengenai pendidikan yang ada salah satunya dalam hal konten materi.

$$
\text { OECD (Organization for }
$$

Economic Co-operation and Development) melakukan survey yang dinakan PISA setiap tiga tahun sekali. Konten materi yang ujikan oleh PISA terdiri dari 3 hal yaitu tes literasi dasar yang mencakup kemampuan membaca, matematis, dan sains. Tes ini diujikan pada anak umur 15 tahun yang ada di berbagai Negara yang dipilih secara acak. Tiga komponen tes yang disajikan PISA ini dianggap mampu untuk menjawab tantangan yang mungkin dihadapi anak-anak di masa yang akan datang (Schleicher, 2018)

Selain tiga literasi dasar yang dianggap penting oleh OECD, organisasi ETS (Educational Testing Service) juga mengemukakan pendapatnya mengenai keterampilan belajar yang berkaitan dengan abad 21, yaitu creative thinking, problem-solving, collaboration, communication. Lebih lanjut ETS juga melmbuat pengelompokan keterampilan literasi digital yang terdiri dari literasi informasi, media, dan ICT (information communication technology).

Keterampilan-keterampilan tersebut kemudian disebut dengan the $4 C s$ atau super skills (Gaston, Station, \& Taylor, n.d.).

Mengingat persaingan global yang semakin ketat dan perkembangan yang semakin pesat, maka menjadi hal yang penting untuk mengimplementasikan keterampilan-keterampilan tersebut pada pembelajaran. Implementasi tersebut perlu ditanamkan sejak sekolah dasar agar anakanak terbiasa dengan kegiatan-kegiatan semacam itu. Konten materi ini dapat menjadi ujung tombak untuk implementasi keterampilan yang tadi sudah disinggung sebelumnya. Tapi yang menjadi tanda tanya, apakah materi yang selama ini diterapkan di sekolah dasar sudah relevan 
dengan keterampilan-keterampilan abad 21 ini?

Berdasarkan uraian di atas dan pertanyaan yang kemudian muncul, penulis merumuskan masalah sebagai berikut: Adakah relevansi materi pokok bahasa Indonesia pada buku tematik kelas 3 revisi 2018 dengan ruang lingkup materi yang berdasarkan Permendikbud No 16 tahun 2016, HOTS (Higher Order Thinking Skills), 4Cs (creative thinking, critical thinking, communication, \& collaboration), literasi baca-tulis, dan literasi digital?

\section{METODOLOGI PENELITIAN}

Penelitian ini menggunakan pendekatan kualitatif dengan jenis analisis wacana khususnya analisis konten materi bahasa Indonesia pada buku tematik kelas 3 revisi 2018. Penelitian ini bertujuan untuk meganalisis relevansi materi pokok bahasa Indonesia yang ada pada buku tematik kelas 3 revisi 2018 dengan beberapa aspek yaitu: (a) ruang lingkup materi berdasarkan Permendikbud No 21 tahun 2016; (b) HOTS (Higher Order Thinking Skills); (c) 4Cs (creative thinking, critical thinking, communication, \& collaboration); (d) literasi baca-tulis; (e) literasi digital. Sumber data penelitian ini adalah dokumen-dokumen berupa buku teks tematik kelas 3 revisi 2018.

Prosedur yang ditempuh pada proses penelitian ini sebagai berikut: (a) studi kepustakaan untuk mempelajari landasan teoritis tentang topik yang diteliti; (b) Mengidentifikasi isi materi pokok bahasa Indonesia buku guru dan buku siswa pada buku tematik kelas 3 revisi 2018 dari tema 1 sampai tema 8; (c) menganalisis kesesuaian isi materi pokok bahasa Indonesia pada buku tematik kelas 3 revisi 2018 dengan beberapa aspek mulai dari ruang lingkup materi, HOTS (Higher Order Thinking Skills), 4Cs (creative thinking, critical thinking, communication, \& collaboration), literasi baca-tulis; dan literasi digital; (d) mengkategorikan data hasil identifikasi berdasarkan aspek-aspek yang sudah disebutkan; (e) menganalisis data yang sudah diidentifikasi dengan aspek-aspek yang sudah disebutkan; (f) menghitung persentase data yang sudah didapatkan dari hasil analisis.

\section{HASIL PENELITIAN DAN PEMBAHASAN \\ Relevansi materi bahasa Indonesia pada buku tematik kelas 3 dengan ruang lingkup materi}

Dalam kurikulum 2013, Bahasa Indonesia tidak hanya difungsikan sebagai alat komunikasi, tetapi juga sebagai sarana berpikir. Bahasa adalah sarana untuk mengekspresikan gagasan dan sebuah gagasan yang utuh biasanya direalisasikan dalam bentuk teks. Teks dimaknai sebagai ujaran atau tulisan yang bermakna, yang memuat gagasan yang utuh. Berdasarkan asumsi tersebut, fungsi pembelajran bahasa adalah mengembangkan kemampuan memahami dan meciptakan teks, karena komunikasi terjadi dalam teks atau pada tataran teks. Pembelajaran berbasis teks inilah yang digunakan sebagai dasar pengembangan mata pelajaran bahasa Indonesia dalam Kurikulum 2013 (Priyatni, 2014, p. 35).

Tabel 1. Persentase analisis materi bahasa Indonesia pada buku Tematik kelas 3 revisi 2018 dengan ruang lingkup materi

\begin{tabular}{clc}
\hline No & \multicolumn{1}{c}{ Ruang Lingkup } & Persentase \\
\hline 1 & Teks deskriptif & $31,25 \%$ \\
\hline 2 & Teks narasi sederhana & $31,25 \%$ \\
\hline 3 & Teks dongeng & $6,8 \%$ \\
\hline 4 & $\begin{array}{l}\text { Teks laporan hasil } \\
\text { observasi }\end{array}$ & $6,8 \%$ \\
\hline 5 & Teks petunjuk/arahan & $4,5 \%$ \\
\hline 6 & Teks instruksi & $4 \%$ \\
\hline 7 & Teks cerita & $2,8 \%$ \\
& diri/personal & $2,8 \%$ \\
\hline 8 & Teks diagram/tabel & $2,8 \%$ \\
\hline 9 & Teks laporan hasil & \\
\hline & pengamatan & $2,4 \%$ \\
\hline 10 & Teks penjelasan proses & $1,7 \%$ \\
\hline 11 & Teks wawancara & $1,7 \%$ \\
\hline 12 & Teks narasi sejarah & $1,2 \%$ \\
\hline 13 & Teks cerita petualangan \\
\hline
\end{tabular}


Hasil analisis materi pokok bahasa Indonesia pada buku tematik belum merata, hal ini berdasarkan persebaran materi yang perbedaannya cukup banyak, materi teks dekskriptif dan teks narasi sederhana masing-masing mendapat persentase $31,25 \%$, sedangkan materi yang lain persentasenya dibawah $10 \%$, teks dongeng dan teks laporan informasi mendapat persentase masing-masing $6,8 \%$, teks petunjuk $4,5 \%$, teks instruksi $4 \%$, teks cerita diri, teks tabel dan teks laporan hasil pengamatan mendapat persentase $2,8 \%$, teks penjelasan hanya mendapat $2,4 \%$, teks wawancara dan narasi sejarah mendapat persentase $1,75 \%$, dan teks cerita petualangan $1,2 \%$.

Analisis menunjukkan bahwa mayoritas materi atau teks yang disajikan dalam materi bahasa Indonesia pada buku tematik kelas 3 banyak menggunakan teks deskriptif dan teks narasi sederhana dengan masing-masing persentase sebanyak $31,25 \%$, teks yang disajikan ada 13 jenis dari 28 teks yang ada pada ruang lingkup materi bahasa Indonesia di sekolah dasar, setidaknya ada $46 \%$ teks yang muncul pada materi bahasa Indonesia di buku tematik kelas 3 .

Teks yang disajikan di sekolah dasar tersebut mengacu pada Permendikbud Nomor 21 tahun 2016 tentang Standar Isi Pendidikan Dasar dan Menengah, isi ruang lingkup materi pokok Bahasa Indonesia MI/SD adalah sebagai berikut (Permendikbud No 21 tahun 2016, 2016):

1. Teks deskriptif

2. Teks petunjuk/arahan

3. Teks terimakasih

4. Teks cerita diri/personal

5. Teks diagram/tabel

6. Teks laporan sederhana

7. Teks narasi sederhana

8. Teks buku harian

9. Teks lirik puisi

10. Teks permintaan maaf

11. Teks laporan hasil observasi

12. Teks surat tanggapan pribadi

13. Teks dongeng
14. Teks permainan/dolanan daerah

15. Teks laporan hasil pengamatan

16. Teks instruksi

17. Teks wawancara

18. Teks cerita petualangan

19. Teks ulasan buku

20. Teks laporan buku

21. Teks penjelasan proses

22. Teks paparan iklan

23. Teks pantun dan syair

24. Teks narasi sejarah

25. Teks laporan investigasi

26. Teks eksplanasi ilmiah

27. Teks pidato persuasive

28. Teks cerita fiksi sejarah

\section{Relevansi materi bahasa Indonesia pada buku tematik kelas 3 dengan HOTS}

HOTS (higher order thinking skills) merupakan keterampilan berpikir tingkat tingggi yang menuntut anak-anak untuk berpikir secara kritis, kreatif, dan analitis berkaitan dengan informasi dan data dalam memecahkan suatu permasalahan (Fanani, A. \& Kusmaharti D., 2018, p. 3).

HOTS menjadi salah satu komponen penting yang perlu dimiliki oleh seorang individu agar mampu menyelesaikan masalah-masalah baru yang muncul di masa yang akan datang (Retnawati, Djidu, Apino, \& Anazifa, 2017, p. 216).

HOTS adalah level tertinggi dalam hierarki proses kognitif. HOTS memungkinkan anak-anak untuk mengatasi tantangan di masa sekarang yang terdapat banyak informasi, tetapi waktu untuk pemrosesannya terbatas (Yee et al., 2015).

Dengan HOTS anak-anak akan mampu untuk membedakan ide atau gagasan dengan jelas, dapat menyampaikan argumennya dengan lancer, dapat membuat hipotesis berkaitan dengan hal-hal yang kompleks agar menjadi lebih jelas, singkatnya HOTS berupaya mengasah kemampuan bernalar anak-anak (Dinni, 2018). 
Beberapa keterampilan dasar yang termasuk dalam HOTS yaitu: (a) berpikir kreatif; (b) berpikir kritis; (c) problem solving; (d) membuat keputusan; (e) mengevaluasi; (f) berpikir logis; (g) berpikir metakognitif; (h) berpikir reflektif; (i) sintesis; (j) analisis kompleks; (k) analisis sistem. Lebih lanjut Lewis dan Smith mengkhususkan cakupan keterampilan tingkat tinggi (HOTS) menjadi empat yaitu berpikir kritis, berpikir kreatif, problem solving, dan membuat keputusan (Sani, 2019, pp. 2-3).

Tabel 2. Persentase analisis materi bahasa Indonesia pada buku Tematik kelas 3 revisi 2018 dengan HOTS

\begin{tabular}{ccc}
\hline No & Kategori HOTS & Persentase \\
\hline 1 & Critical thinking & $66,7 \%$ \\
\hline 2 & Creative thinking & $25 \%$ \\
\hline 3 & Problem Solving & $8,3 \%$ \\
\hline 4 & Decision making & $0 \%$ \\
\hline
\end{tabular}

Empat kategori dari keterampilan HOTS menunjukkan persentase yang berbeda-beda akan tetapi tidak merata, pada keterampilan critical thinking persentasenya paling besar bahkan di atas $50 \%$ yaitu $66,7 \%$, keterampilan creative thinking mendapat persentase $25 \%$, keterampilan problem solving mendapat persentase $8,3 \%$, dan decision making tidak terlihat di materi bahasa Indonesia pada buku tematik kelas 3 .

Analisis menunjukkan bahwa persentase tertinggi dari empat kategori HOTS yaitu ada pada keterampilan berpikir kritis dengan persentase sebesar $66,7 \%$, hal ini jelas tidak terdengar baik karena persentasenya tidak imbang, padahal empat keterampilan ini diperlukan secara keseluruhan oleh anak-anak untuk dapat berkembang lebih jauh, dan perlu diterapkan sedini mungkin agar mereka terbiasa dengan kegiatan yang menuntut kemampuan tingkat tiggi, dengan tetap menyesuaikan aspek perkembangannya.

\section{Relevansi materi bahasa Indonesia pada buku tematik kelas 3 dengan $4 \mathrm{Cs}$}

Keterampilan 4Cs ini perlu dimiliki karena menjadi kunci utama untuk dapat beradaptasi dengan baik pada masa modern ini (Rusdin, Ali, Rusdin, \& Ali, 2019). Keterampilan 4Cs atau super skills ini dimaknai sebagai keterampilan abad 21 yang di dalamnya mencakup empat keterampilan dasar yang perlu dimiliki agar mampu untuk terus berkembang pada masa sekarang dan yang akan datang (Kivunja, 2015).

Berpikir kreatif dapat dimaknai dengan keterampilan berpikir yang dapat menghubungkan atau melihat sesuatu dari sudut pandang yang berbeda bahkan sudut pandang baru (Susanto, 2013, p. 109). Berpikir kreatif dapat didefinisikan sebagai seluruh rangkaian kegiatan kognitif yang digunakan oleh individu sesuai dengan objek, masalah, dan kondisi tertentu, atau suatu upaya menuju peristiwa tertentu dan menguraikan masalah berdasarkan kapasitas individu (Yazar, 2015).

Selanjutnya dipaparkan mengenai perilaku anak kreatif yang memiliki tingkat intelegensi tinggi yaitu memiliki rasa ingin tahu yang tinggi, tanggap dalam menyelesaikan persoalan, hati-hati dalam mengambil tindakan, bersemangat dalam memecahkan masalah, cenderung menyukai tantangan, selalu berusaha menjadi lebih baik, ingin melakukan atau membuat sesuatu yang baru, memiliki sensitivitas yang tinggi, dan fleksibel (Susanto, 2013, pp. 117-118).

Anggelo berpendapat bahwa berpikir kritis adalah mengaplikasikan rasional, kegiatan berpikir tinggi yang meliputi kegiatan menganalisis, menyintesis, mengenal permasalahan dan pemecahannya, menyimpulkan, dan mengevaluasi (Susanto, 2013, p. 112). Keterampilan berpikir kritis dapat membentuk sesorang menjadi ahli dalam mengembangkan kemampuan dasar yang di dapatkannya (Tiruneh, Verburgh, \& Elen, 2014). 
Nickerson mengemukakan beberapa ciri siswa yang memiliki keterampilan berpikir kritis yaitu (a) mengakui keterbatasan diri; (b) melihat masalah sebagai tantangan yang menarik; (c) menjadikan pemahaman sebagai tujuan; (d) menggunakan bukti untuk membuat pertimbangan; (e) tertarik pada ide orang lain; (f) berpikir sebelum bertindak; (g) menghindari sikap emosional; (h) berpikiran terbuka; (i) mampu mendengarkan secara aktif (Sani, 2019, p. 82).

Kolaborasi berasal dari bahasa Latin "kolaborasi" dan sarana untuk bekerja sama. Keunggulan dan tantangan yang dicapai dalam upaya penerapan kegiatan collaboration pembelajaran yaitu akan ada dampak positif dalam meningkatkan pembangan kemampuan kognitif dan psikologis (Zandvakili, Washington, Gordon, Wells, \& Mangaliso, 2019). Collaboration dalam keterampilan 4Cs dipahami sebagai kemampuan bekerja sama di sebuah kelompok dalam upaya memecahkan suatu permasalahan yang ada.

Grup kecil dapat didefinisikan sebagai dua atau lebih banyak individu yang melakukan kegiatan seperti (a) berinteraksi satu sama lain; (b) saling tergantung; (c) mendefinisikan diri mereka sendiri dan didefinisikan oleh orang lain sebagai anggota kelompok; (d) berbagi norma tentang hal-hal yang menjadi kepentingan bersama dan berpartisipasi dalam sistem peran yang saling terkait; (e) saling mempengaruhi; (f) menemukan kelompok yang dihargai; dan (g) mengejar kesamaan tujuan (Styron, 2014).

Communication dipahami sebagai upaya untuk mengkomunikasikan ide-ide dan gagasan secara efektif menggunakan media lisan, tertulis, maupun teknologi (Ariana et al., 2018, p. 14). Komunikasi adalah transmisi makna dari satu orang ke orang lain atau ke banyak orang, baik itu secara verbal atau non-verbal (Matin, Jandaghi, Karimi, \& Hamidizadeh, 2010).
Karakteristik

komunikasi

diantaranya:

Keterampilan mengartikulasikan pemikiran dan ide secara efektif menggunakan lisan, tulisan dan keterampilan komunikasi nonverbal dalam berbagai bentuk dan konteks; (b) mendengarkan secara efektif untuk menguraikan makna, termasuk pengetahuan, nilai-nilai, sikap dan niat; (c) menggunakan komunikasi untuk suatu variasi tujuan; (d) memanfaatkan berbagai media dan teknologi, dan tahu bagaimana menilai apriori efektivitas mereka serta menilai dampaknya; (e) berkomunikasi secara efektif di lingkungan yang beragam (termasuk multibahasa) (Handajani, Pratiwi, \& Mardiyana, 2018).

Kemampuan untuk berkomunikasi dan berkolaborasi adalah penting karena siswa dituntut untuk dapat menjadi bagian dari masyarakat. Ini sangat wajar karena dalam kehidupan sosial ada akan ada berbagai macam masalah yang harus dikritik siswa dan tunggu solusi yang tepat untuk menyelesaikan masalah. Solusi akan dirancang dan diimplementasikan oleh orang-orang yang kreatif dan mampu berpikir kritis (Kembara, Rozak, \& Hadian, 2019).

Tabel 3. Persentase analisis materi bahasa Indonesia pada buku Tematik kelas 3 revisi 2018 dengan 4C

\begin{tabular}{cll}
\hline No & Kategori 4C & Persentase \\
\hline 1 & Critical thinking & $40,5 \%$ \\
\hline 2 & Creative thinking & $15,2 \%$ \\
\hline 3 & Communication & $16,5 \%$ \\
\hline 4 & Collaboration & $27,8 \%$ \\
\hline
\end{tabular}

Kegiatan pembelajaran yang muncul pada materi bahasa Indonesia di buku temati kelas 3 dan berkaitan dengan keterampilan 4C sudah cukup baik dengan persentase yang cukup rata, meski untuk keterampilan critical thinking mendapat persentase yang diatas rata-rata lainnya yaitu 40,5\%, sedangkan keterampilan collaboration mendapat persentase $27,8 \%$, keterampilan communication mendapat 
persentase $16,5 \%$, dan creative thinking mendapat persentase $16,5 \%$.

Berdasarkan hasil analisis yang dilakukan, kegiatan-kegiatan pada materi bahasa Indonesia di buku tematik kelas 3 cenderung mengarah kepada critical thinking, hal ini dibuktikan dengan hasil persentase critical thinking yang sebesar $40,5 \%$, kegiatan yang selanjutnya sering dimunculkan yaitu collaboration dengan persentase sebesar 27,8\%, ketiga communication dengan persentase sebesar $16,5 \%$, keempat creative thinking dengan persentase sebesar $15,2 \%$.

\section{Relevansi materi bahasa Indonesia pada buku tematik kelas 3 dengan literasi baca-tulis}

Literasi berperan penting bagi kehidupan manusia ditinjau dari pengembangan sosial dan perbaikan kehidupan agar dapat meningkatkan kesehatan, penghasilan, dan hubungannya dengan lingkungan global (Indriyani, Zaim, \& Ramadhan, 2019).

Dalam konsep literasi, membaca ditafsirkan sebagai usaha memahami, menggunakan, merefleksi, dan melibatkan diri dalam berbagai jenis teks untuk mencapai suatu tujuan. Dalam hal ini, membaca bertujuan mengembangkan pengetahuan dan potensi seseorang, serta utuk berpartisipasi dalam masyarakat. Berdasarkan definisi ini, membaca diartikan sebagai kegiatan membangun makna, menggunakan informasi dari bacaan secara langsung dalam kehidupan, dan mengaitkan informasi dari teks dengan pengalaman pembaca (Abidin, Mulyati, \& Yunansah, 2018, p. 165)

Penilaian membaca dilakukan oleh PISA (The Programme for International Student Assesment). PISA menitik beratkan kemampuan literasi membaca dengan konsep membaca cermat. Frey dan Fisher mendefinisikan membaca cermat sebagai kegiatan praktis sitematis dalam menganalisis teks untuk mendapatkan pemahaman yang mendalam (Abidin et al., 2018, p. 169). PISA juga mengadaptasi empat variabel situasi dari Common European Framework of Reference (CEFR) yang dikembangkan untuk OECD meliputi situasi pribadi, publik, pendidikan, dan dunia kerja.

Ditinjau dari aspeknya, penilaian literasi membaca mengukur lima aspek sebagai berikut (a) kemampuan mengambil informasi; (b) kemampuan membentuk pemahaman yang luas; (b) kemampuan mengembangkan interpretasi; (d) kemampuan merefleksikan dan mengevaluasi isi teks; (e) kemampuan merefleksikan dan mengevaluasi bentuk teks (Abidin et al., 2018, pp. 256-257).

Dalam konsep literasi, menulis merupakan proses berulang yang dilakukan penulis untuk merevisi ideidenya, mengulangi tahapan-tahapan menulis, hingga mampu mencurahkan ide dan gagasan atau ide yang dikembangkannya (Abidin et al., 2018, p. 206).

Ditinjau dari dimensi atau aspeknya, penilaian literasi menulis mengukur minimalnya lima aspek yaitu (a) isi atau konten keilmuan; (b) data dan fakta; (c) logika, opini, tanggapan, ataupun kritik; (d) struktur tulisan; (e) bahasa; (f) teknis penulisan dan media representasi (Abidin et al., 2018, p. 266).

Tabel 4. Tabel Persentase analisis materi bahasa Indonesia pada buku Tematik kelas 3 revisi 2018 dengan literasi baca-tulis

\begin{tabular}{cll}
\hline No & Kategori Literasi & Persentase \\
\hline 1 & Literasi membaca & $78,9 \%$ \\
\hline 2 & Literasi menulis & $21,1 \%$ \\
\hline
\end{tabular}

Berdasarkan hasil analisis yang dilakukan, kegiatan literasi membaca lebih banyak ditunjukkan pada materi bahasa Indonesia di buku tematik kelas III dengan persentase sebesar 78,9\%, sedangkan untuk kegiatan literasi menulis menunjukkan persentase sebesar $21,1 \%$.

Persentase yang hasilnya kira-kira 1:3 itu terlihat kurang baik mengingat 
kemampuan menulis anak sebaiknya mulai diterapkan sejak dini, agar mereka terbiasa menulis, sehingga ketika beranjak remaja sudah mampu mengarang teks yang lebih kompleks.

Kemampuan menulis yang diterapkan pada materi bahasa Indonesia kelas 3 masih pada tingkat sederhana seperti menyusun pertanyaan untuk wawancara, menulis cerita dari kosakata baru yang didapatkannya, dan menceritakan hasil pengamatan dengan bahasanya sendiri melalui bahasa tulis.

\section{Relevansi materi bahasa Indonesia pada buku tematik kelas 3 dengan literasi digital}

Dalam kaitannya dengan

pendidikan, perkembangan ICT

(information communication technology)

dapat memberi ruang untuk anak-anak mendapatkan pengalaman yang baru dalam belajar maupun interaksi sosialnya.

Gilster mendefinisikan bahwa literasi digital merupakan kemampuan untuk memahami dan menggunakan informasi dalam berbagai format yang berasal dari berbagai sumber yang sangat luas yang disajikan melalui media elektronik (Harjono, 2013, p. 3).

Berkaitan dengan literasi digital, Belshaw mengungkapkan bahwa terdapat delapan elemen penting untuk mengembangkan keterampilan dalam literasi digital (Ariyana, Bestary, Yogyakarta, \& Mohandas, n.d., p. 7), yaitu:

a. Kultural, yaitu pemahaman mengenai keragaman pengguna dunia digital

b. Kognitif, yaitu kemampuan pikiran dalam menilai konten

c. Konstruktif, yaitu perancangan sesuatu yang ahli dan actual

d. Komunikatif, yaitu memahami kinerja jejaring dan komunikasi di dunia digital

e. Kepercayaan diri yang bertanggung jawab

f. Kreatif g. Kritis dalam menyikapi konten

h. Bertanggung jawab secara sosial

Berkaitan dengan analisis materi pokok pada buku tematik kelas 3 dengan literasi digital ditemukan satu bagian yang berkaitan dengan literasi digital yaitu pada tema 7 (Perkembangan Teknologi) subtema 3 (Perkembangan Teknologi dan Komunikasi).

Pada tema 7 subtema 3, literasi digital dibahas cukup lengkap untuk tingkat perkembangan anak kelas 3 , materi yang disajikan diantaranya sejarah alat komunikasi mulai dari surat tertulis sampai media elektronik, terdapat juga materi yang mengarahkan peserta didik untuk bijak dalam menggunkan media sosial.

\section{KESIMPULAN}

Berdasarkan hasil analisis di atas, maka dapat disimpulkan bahwa materi pokok bahasa Indonesia pada buku tematik kelas III tingkat MI/SD sudah cukup relevan dengan beberapa aspek yang menjadi pertimbangan seperti ruang lingkup materi, HOTS, 4Cs, literasi bacatulis, dan literasi digital. Meski masih terdapat bebrapa hal yang memiliki kekurangan seperti ruang lingkup materi yang sudah belum memasukkan secara keseluruhan teks yang seharusnya tapi setidaknya ada $46 \%$ materi yang tersampaikan. Relevansi materi dengan HOTS belum optimal dibuktikan dengan keterampilan critical thinking yang menjadi mayoritas sebesar $66,7 \%$ sedangkan lainnya persentasenya kecil bahkan untuk keterampilan decision making tidak ada. Relevansi dengan keterampilan 4C sudah cukup merata dengan persentase critical thinking sebesar $40,5 \%$, creative thinking sebesar $15,2 \%$, communication sebesar 16,5\%, dan collaboration $27,8 \%$. Relevansi dengan literasi baca-tulis masih kurang imbang terlihat dari persentase literasi membaca yang sebesar $78,9 \%$ dan literasi menulis yang sebesar $21,1 \%$ dengan perbandingan keduanya yaitu kurang lebih 1:3. Relevansinya dengan literasi digital cukup 
baik, setidaknya ada satu subtema yang membahas teknologi dan komunikasi yaitu pada tema 7 subtema 3 , meski masih pada tahap pengenalan sejarah dan alat komunikasinya.

\section{DAFTAR PUSTAKA}

Abidin, Y., Mulyati, T., \& Yunansah, H. (2018). Pembelajaran Literasi: Strategi Meningkatkan Kemampuan Literasi Matematika, Sains, Membaca, dan Menulis (Y. N. I. Sari, ed.). Jakarta: Bumi Aksara.

Ariyana, Y., Bestary, R., Yogyakarta, U. N., \& Mohandas, R. (n.d.). Buku Pegangan Pembelajaran HOTS 2018.

Dinni, H. N. (2018). HOTS ( High Order Thinking Skills ) dan Kaitannya dengan Kemampuan Literasi Matematika. Prisma, 1, 170-176.

Fanani, A. \& Kusmaharti D. (2018). Pengembangan Pembelajaran Berbasis HOTS (Higher Order Thinking Skills) di Sekolah Dasar Kleas V. JPD: Jurnal Pendidikan Dasar, 9(No 1), 1-11. Retrieved from http://journal.unj.ac.id/unj/index.php/j pd/article/view/JPD.91.01

Gaston, P., Station, F., \& Taylor, L. A. (n.d.). Digital Transformation A Framework for ICT Literacy ICT Literacy Panel.

Handajani, S., Pratiwi, H., \& Mardiyana, M. (2018). The 21 st century skills with model eliciting activities on linear program. Journal of Physics: Conference Series, 1008(1). https://doi.org/10.1088/17426596/1008/1/012059

Harjono, H. S. (2013). Literasi Digital: Prospek dan Implikasinya dalam Pembelajaran Bahasa. Pena: Jurnal Pendidikan Bahasa Dan Sastra, 8(No 1), 1-7. Retrieved from https://www.onlinejournal.unja.ac.id/pena/issue/view/81 8

Indriyani, V., Zaim, M., \& Ramadhan, S. (2019). Literasi Baca Tulis Dan Inovasi Kurikulum Bahasa. 5(1),
108-118.

Kembara, M. D., Rozak, R. W. A., \& Hadian, V. A. (2019). Researchbased Lectures to Improve Students' $4 C$ (Communication, Collaboration, Critical thinking, and Creativity) Skills. 306(Isseh 2018), 22-26. https://doi.org/10.2991/isseh18.2019 .6

Kivunja, C. (2015). Exploring the Pedagogical Meaning and Implications of the 4Cs "Super Skills" for the 21st Century through Bruner's 5E Lenses of Knowledge Construction to Improve Pedagogies of the New Learning Paradigm. Creative Education, 06(02), 224-239. https://doi.org/10.4236/ce.2015.6202 1

Matin, H. Z., Jandaghi, G., Karimi, F. H., \& Hamidizadeh, A. (2010). Relationship between interpersonal communication skills and organizational commitment (Case study: Jahad keshavarzi and university of Qom, Iran). European Journal of Social Sciences, 13(3), 387-398.

Permendikbud No 21 tahun 2016. (2016).

Priyatni, T. E. (2014). Desain Pembelajaran Bahasa Indonesia dalam Kurikulum 2013. Jakarta: PT Bumi Aksara.

Retnawati, H., Djidu, H., Apino, E., \& Anazifa, R. D. (2017). Teachers knowledge about higher-order thinking skills and. 7864.

Rusdin, N. M., Ali, S. R., Rusdin, N. M., \& Ali, S. R. (2019). Practice of Fostering 4Cs Skills in Teaching and Learning Practice of Fostering 4Cs Skills in Teaching and Learning. 9(6), 1021-1035.

https://doi.org/10.6007/IJARBSS/v9i6/6063

Sani, R. A. (2019). Pembelajaran Berbasis HOTS (Higher Order Thinking Skills). Tangerang: Tira Smart.

Schleicher, A. (2018). Insights and Interpretations. 
Styron, R. A. (2014). Critical thinking and Collaboration: A Strategy to Enhance Student Learning. Systemics, Cybernetics and Informatics, 12(7), 561-565.

Susanto, A. (2013). Teori Belajar dan Pembelajaran di Sekolah Dasar. Jakarta: Kencana.

Tiruneh, D. T., Verburgh, A., \& Elen, J. (2014). Effectiveness of Critical thinking Instruction in Higher Education: A Systematic Review of Intervention Studies. 4(1). https://doi.org/10.5539/hes.v4n1p1

Yazar, S. B. B. (2015). Creative and Critical thinking Skills in Problembased Learning Environments. Journal of Gifted Education and Creativity, 2 (2), 71-71. https://doi.org/10.18200/jgedc.20152 $\underline{14253}$

Yee, M. H., Yunos, J. M., Othman, W., Hassan, R., Tee, T. K., \& Mohamad, M. M. (2015). Disparity of Learning Styles and Higher Order Thinking Skills among Technical Students. Procedia - Social and Behavioral Sciences, 204 (November 2014), 143-152.

https://doi.org/10.1016/j.sbspro.2015. $\underline{08.127}$

Zandvakili, E., Washington, E., Gordon, E. W., Wells, C., \& Mangaliso, M. (2019). Teaching Patterns of Critical thinking: The 3CA Model - Concept Maps, Critical thinking, Collaboration, and Assessment. https://doi.org/10.1177/21582440198 $\underline{85142}$ 